\title{
The Effects of Colostrum on Gastrointestinal Function and Related Diseases in Premature Infants: A Comprehensive Meta-Analysis of Randomized Controlled Trials
}

\author{
Rong Tang, Xiaoyun Yao, Lanping Shi* \\ Department of Medicine, Yangtze University, Jinzhou, China \\ Email: 1129934527@qq.com, *shilp@hku-szh.org
}

How to cite this paper: Tang, R., Yao, X.Y. and Shi, L.P. (2018) The Effects of Colostrum on Gastrointestinal Function and Related Diseases in Premature Infants: A Comprehensive Meta-Analysis of Randomized Controlled Trials. Yangtze Medicine, 2, 271-280.

https://doi.org/10.4236/ym.2018.24029

Received: August 23, 2018

Accepted: December 18, 2018

Published: December 21, 2018

Copyright $\odot 2018$ by authors and Scientific Research Publishing Inc. This work is licensed under the Creative Commons Attribution International License (CC BY 4.0).

http://creativecommons.org/licenses/by/4.0/

\section{c) (i) Open Access}

\begin{abstract}
Aim: To systematically evaluate the effects of colostrum intervention on gastrointestinal function and related diseases in premature infants. Methods: A randomized controlled trial was conducted in the Cochrane Library, PubMed, EBSCO, CINAHL, Embase, Medline, CBMDISC, CNKI, Wan Fang and VIP databases on the effects of colostrum and oral intervention on gastrointestinal function and related diseases in premature infants. Literature screening, quality evaluation and data extraction were conducted, and data analysis was conducted using Revman 5.3. Results: A total of 7 references were included, including 392 subjects. The combined results showed that: colostrum can effectively reduce the incidence of nosocomial infection $[R R=0.42,95 \% \mathrm{CI}$ $(0.25,0.73), P=0.002]$. Conclusion: Colostrums oral intervention can effectively reduce the incidence of nosocomial infection in premature infants. However, there was no advantage in feeding intolerance, necrotizing enters colitis and length of hospital stay.
\end{abstract}

\section{Keywords}

Colostrums Oral Intervention, Gastrointestinal Function, Meta-Analysis, System Review

\section{Introduction}

The World Health Organization (WHO) reported that 15 million premature babies born every year in May 2012 [1]. However, due to the immature digestive system of premature infants, most of them adopt nasal feeding or total parenter- 
al nutrition to support life. Although meeting the nutritional needs of premature infants, feeding intolerance, necrotizing enter colitis and other diseases are easy to occur. Therefore, safe and effective oral feeding becomes the ultimate goal of premature infants [2]. Studies have shown that oral interventions are sensory stimulation of the lips, jaw, tongue, soft palate, and throat. It can effectively shorten the time from tube feeding to oral feeding for premature infants. If the colostrums are combined with oral intervention, the abundant cytokines in colostrums and immunocompetent cell such as lactoferrin can be fully absorbed in the cheek of premature infant [3] [4] [5] [6]. It can not only strengthen the resistance of premature infants to pathogenic microorganisms but also effectively improve the feeding process [7] [8]. However, due to different intervention measures, frequency and duration of studies, the effects of colostrum intervention on gastrointestinal function and related diseases in premature infants are different. The related studies at home and abroad are collected and summarized to provide evidence basis for clinical nursing. The report is as follows.

\section{Material and Methods}

\subsection{Search Strategy and Study Selection}

According to the keywords ("premature OR immature delivery OR low birth weight (LBW) OR very low birth weight (VLBW)") AND ("colostrum oral feeding OR colostrum oral intervention OR colostrum oral drip OR colostrum oral daub OR Oropharyngeal Administration") AND ("gastrointestinal function OR digestive function"). With the language limited to English and Chinese, we retrieved the related articles from Cochrane Library, PubMed, EBSCO, CINAHL, Embase, Medline, Sino Med, CNKI, Wan Fang and VIP from their database inception to April 2018.

Retrieve the steps: 1) System review or meta-analysis of the oral colostrum intervention in the Cochrane Library was searched. 2) Relevant original documents included in Chinese and English databases such as PubMed and EBSCO were searched, and the title, abstract and key words of the obtained articles were analyzed to further determine the keywords. 3) Retrieve the above database using mesh words OR keywords, and use the "AND", "OR", "NOT" operators if necessary. 4) Manually search for references in the published literature.

Study selection was required to meet the following inclusion criteria: 1) The study must be Randomized Controlled trials (RCT). 2) The object of study were premature infants, A live birth of a baby less than 37 week of gestational age, weight is less than $2500 \mathrm{~g} .1500 \mathrm{~g}-2500 \mathrm{~g}$ are called low weight children, $<1500 \mathrm{~g}$ are extremely low weight children [3] [4]. 3) The intervention method must have two conditions, one is the use of colostrums, and the other is oral intervention. The frequency, dose and duration of intervention should be described. 4) outcome indicator: a) Gestational age at the time of complete non-retention; b) Incidence of feeding intolerance, Patients with feeding intolerance without a clear definition are characterized by gastric retention, vomiting and abdominal dis- 
tension [8]; c) Incidence of nosocomial infections, septicemia [9]; d) The incidence of necrotizing enterocolitis; e) LOS (length of stay); f) Secretary immunoglobulin A (slgA); g) lactoferrin.

Exclusion criteria: 1) The studied that do not include outcome measures; 2) Repeated publication; 3) Unable to extract data or obtain full text; 4) The babies with congenital diseases or malformations or whose guardians cannot provide colostrums.

\subsection{Quality Assessment and Date Extraction}

All literature quality evaluations were completed by 2 researchers trained in an evidence-based nursing course. Firstly, the included literature was evaluated independently according to the evaluation criteria of Cochrane evaluation manual 5.1.0 [10]. When disagreements arise, discuss inclusion or exclusion. If the above criteria are fully met, the probability of occurrence of various biases is small, grade A. if partial; the probability of occurrence of bias is moderate, grade $\mathrm{B}$. The probability of bias is higher, which is grade C. A, B can be used, C can be excluded. Recommended level: A > B > C.

Two researchers developed standardized tables based on literature content and independently extracted data. Including the year, author, sample size, intervention measures, frequency of intervention, dose used for intervention, intervention method, and duration and outcome index of the included literature.

\subsection{Statistical Analysis}

The Revman 5.3 software was used for Meta analysis, Weighted Mean Differences (WMD) was used to analyze the continuous data of the same measurement tools, and otherwise Standardized Mean Differences (SMD) was used. Calculation of relative risk (RR) for binary classification data, all analyses calculated $95 \% \mathrm{CI}$, for studies without methodological and clinical heterogeneity; statistical heterogeneity was determined by the calculation of $\mathrm{I}^{2}$ by Cochrane $\mathrm{Q}$ test. If the heterogeneity between studies was small ( $\left.\mathrm{P}>0.1, \mathrm{I}^{2}<50 \%\right)$, fixed model was used. If the heterogeneity is large ( $\left.\mathrm{P} \leq 0.1, \mathrm{I}^{2} \geq 50 \%\right)$, the random model is used. If the sources of heterogeneity cannot be determined, or heterogeneity is significant, only descriptive analysis is conducted.

\section{Result}

\subsection{Search Results and Study Characteristics}

By April 2018, a total of 2682 literalness had been retrieved, Repeated publication, literature review, and irrelevant literature $(\mathrm{n}=2324)$ were deleted, with 358 remaining articles, Read the title, abstract, and exclude the descriptive study and the study without control group $(\mathrm{n}=256)$, read the full article to exclude data incompleteness, remaining 5 articles, 2 articles were obtained by manually searching references, and 7 articles were finally included [9] [11]-[16]. There are 5 Chinese [12] [13] [14] [15] [16] articles and 2 English articles [9] [11]. The 
screening process is shown in Figure 1. In one article [15], the intervention group was divided into high frequency group and low frequency group, In order to make the data more clear and split into two RCT, the basic features of the included articles are shown in Table 1.

\subsection{Quality Evaluation of Included Literature}

The included RCT was evaluated and graded according to the evaluation criteria of Cochrane evaluation manual 5.1.0. The methodological quality of the included articles is mostly medium, and the specific evaluation indicators and results are shown in Table 2.

Table 1. Basic characteristics of the included literature.

\begin{tabular}{|c|c|c|c|c|c|c|c|}
\hline \multirow{2}{*}{ study } & \multirow{2}{*}{ year } & \multicolumn{2}{|c|}{ sample size } & \multicolumn{3}{|c|}{ intervention measure } & \multirow{2}{*}{$\begin{array}{l}\text { outcome } \\
\text { indicator }\end{array}$} \\
\hline & & IG & CG & IG & CG & frequency & \\
\hline F. T. Ji [12] & 2016 & 28 & 27 & Oral drip of colostrum & Saline drip & $\begin{array}{c}\text { Once every } 4 \mathrm{~h} \\
0.2 \mathrm{ml} \text { each time, for seven days }\end{array}$ & A, B \\
\hline X. J. Zhao [13] & 2017 & 20 & 20 & Oral drip of colostrum & Saline drip & $\begin{array}{c}\text { Once every } 4 \mathrm{~h} \\
0.2 \mathrm{ml} \text { each time, for seven days }\end{array}$ & A \\
\hline C. Y. Chen [14] & 2018 & 46 & 46 & Oral drip of colostrum & Saline drip & $\begin{array}{c}\text { Once every } 4 \mathrm{~h} \text {, } \\
0.2 \mathrm{ml} \text { each time, for seven days }\end{array}$ & A, B, C, D \\
\hline S. X. Cao [15] & 2018 & 20 & 20 & Colostrum oral smear & Sterile water smear & $\begin{array}{l}\text { Once every } 3 \mathrm{~h} \\
\text { Once every } 6 \mathrm{~h}\end{array}$ & $\mathrm{~B}, \mathrm{E}$ \\
\hline L. F. Chen [16] & 2017 & 30 & 30 & Colostrum oral smear & Normal saline smear & Once every $3 \mathrm{~h}$, for two weeks & $\mathrm{B}, \mathrm{C}, \mathrm{D}, \mathrm{E}$ \\
\hline Y. X. Zhang [9] & 2017 & 27 & 28 & Oral drip of colostrum & Saline drip & $\begin{array}{c}\text { Once every } 4 \mathrm{~h} \text {, } \\
0.2 \mathrm{ml} \text { each time, For seven days }\end{array}$ & $\mathrm{C}, \mathrm{E}, \mathrm{G}, \mathrm{H}$ \\
\hline Glass K. [11] & 2017 & 17 & 13 & Oral drip of colostrum & Sterile drop injection & Once every $3 \mathrm{~h}, 0.2 \mathrm{ml}$ each time & C, E, G, H \\
\hline
\end{tabular}

Note: IG: Intervention group. CG: Control group. A: Gestational age at the time of complete non-retention. B: Incidence of feeding intolerance. C: Incidence of nosocomial infection. D: The incidence of necrotizing enters colitis. E: LOS (length of stay). G: Secretary immunoglobulin A (slgA). H: lactoferrin.

Table 2. Methodological quality evaluation for inclusion of RCT.

\begin{tabular}{|c|c|c|c|c|c|c|c|c|}
\hline Sample & $\begin{array}{l}\text { Random } \\
\text { sequence } \\
\text { generation }\end{array}$ & $\begin{array}{l}\text { Allocation } \\
\text { concealment }\end{array}$ & $\begin{array}{c}\text { Blinding of } \\
\text { participants and } \\
\text { personnel }\end{array}$ & $\begin{array}{l}\text { Blind of outcome } \\
\text { assessment }\end{array}$ & $\begin{array}{l}\text { Incomplete } \\
\text { outcome date }\end{array}$ & $\begin{array}{l}\text { Selective } \\
\text { reporting }\end{array}$ & $\begin{array}{l}\text { Other } \\
\text { sources } \\
\text { of bias }\end{array}$ & $\begin{array}{c}\text { Quality } \\
\text { grade }\end{array}$ \\
\hline F. T. Ji [12] & $\mathrm{U}$ & $\mathrm{U}$ & $\mathrm{L}$ & $\mathrm{L}$ & $\mathrm{H}$ & $\mathrm{L}$ & $\mathrm{U}$ & B \\
\hline X. J. Zhao [13] & $\mathrm{H}$ & $\mathrm{U}$ & $\mathrm{L}$ & $\mathrm{L}$ & $\mathrm{L}$ & $\mathrm{L}$ & $\mathrm{U}$ & B \\
\hline C. Y. Chen [14] & $\mathrm{L}$ & $\mathrm{U}$ & $\mathrm{L}$ & $\mathrm{L}$ & $\mathrm{L}$ & $\mathrm{L}$ & $\mathrm{U}$ & B \\
\hline S. X. Cao [15] & $\mathrm{L}$ & $\mathrm{U}$ & $\mathrm{L}$ & $\mathrm{L}$ & $\mathrm{L}$ & $\mathrm{L}$ & $\mathrm{U}$ & B \\
\hline L. .F Chen [16] & $\mathrm{U}$ & U & $\mathrm{L}$ & $\mathrm{L}$ & $\mathrm{L}$ & $\mathrm{L}$ & $\mathrm{U}$ & B \\
\hline Y. X. Zhang [9] & $\mathrm{L}$ & $\mathrm{L}$ & $\mathrm{L}$ & $\mathrm{L}$ & $\mathrm{L}$ & $\mathrm{L}$ & $\mathrm{L}$ & A \\
\hline Glass K. [11] & $\mathrm{L}$ & U & $\mathrm{L}$ & $\mathrm{L}$ & $\mathrm{L}$ & $\mathrm{L}$ & $\mathrm{U}$ & B \\
\hline
\end{tabular}

Note: L, Low risk of bias. U, Unclear risk of bias. H, High risk of bias. 


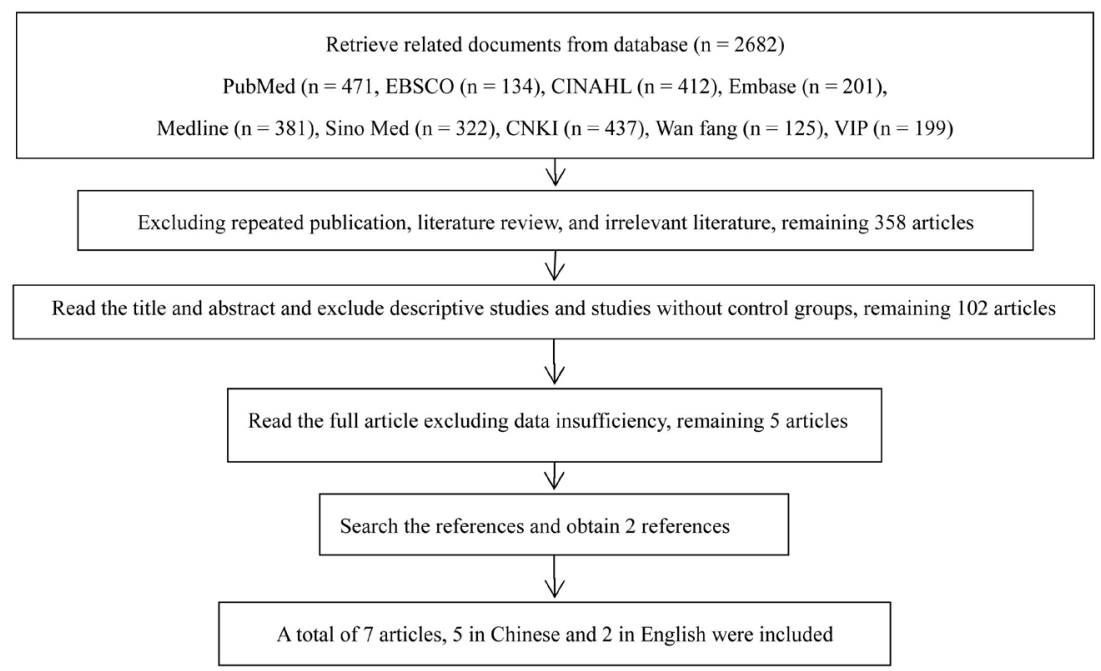

Figure 1. Literature screening flow chart.

\subsection{Basic Features of the Included Literature}

A total of 392 premature infants were included in 7 literatures. 3 [12] [13] [14] reported gestational age at the time of complete non-retention, 5 RCT [12] [14] [15] [16] reports feeding intolerance, 4 articles [9] [11] [14] [16] reported hospital infection rate, 4 articles [9] [11] [15] [16] reported hospitalization duration, 2 articles [14] [16] reported the incidence of necrotic enter colitis, and 2 articles [9] [11] reported lactoferrin and slgA. The basic characteristics of the included articles are shown in Table 1.

\subsection{Effect Evaluation of Colostrums Oral Intervention}

\subsubsection{Effect on Gestational Age at Complete Non-Retention}

3 [12] [13] [14] reported the effect of colostrums intervention on the gestational age of premature infants with complete non-retention. The results of data combination showed that there was heterogeneity between the studies $\left(\mathrm{P}=0.13, \mathrm{I}^{2}=\right.$ $50 \%$ ), and the random model was adopted. The results showed that the intervention of colostrums can reduce the time of complete non-retention and improve the gastrointestinal function of premature infants. The difference between the two groups was statistically significant $[\mathrm{MD}=-1.13,95 \% \mathrm{CI}(-2.17,-0.10), \mathrm{P}=$ 0.03]. As shown in Figure 2.

\subsubsection{Effect of Colostrums Oral Intervention on Nosocomial Infection} 4 [9] [11] [14] [16] reported the influence of colostrums intervention on the nosocomial infection rate of premature infants, and the combined results showed that the inter-study heterogeneity was relatively small $\left(\mathrm{P}=0.17, \mathrm{I}^{2}=40 \%\right)$. Therefore, the fixed model was selected, and the results showed that colostrum intervention could effectively reduce the nosocomial infection rate of premature infants $[R R=0.42,95 \% \mathrm{CI}(0.25,0.73), \mathrm{P}=0.002]$. As shown in Figure 3.

\subsubsection{Effect of Colostrums Oral Intervention on Immune Function}

SlgA and lactoferrin were used as evaluation indicators in 2 papers [9] [11], 


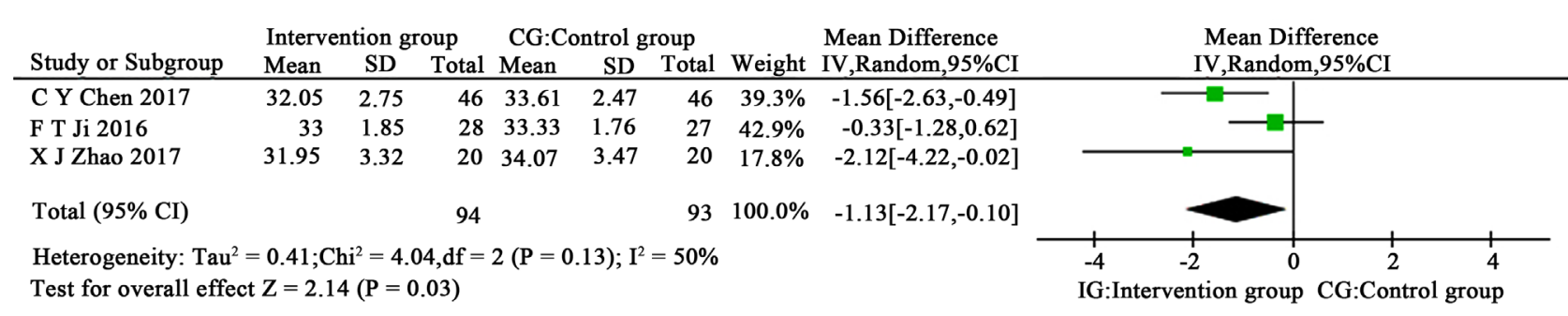

Figure 2. Effect on gestational age of premature infants with complete non-retention.

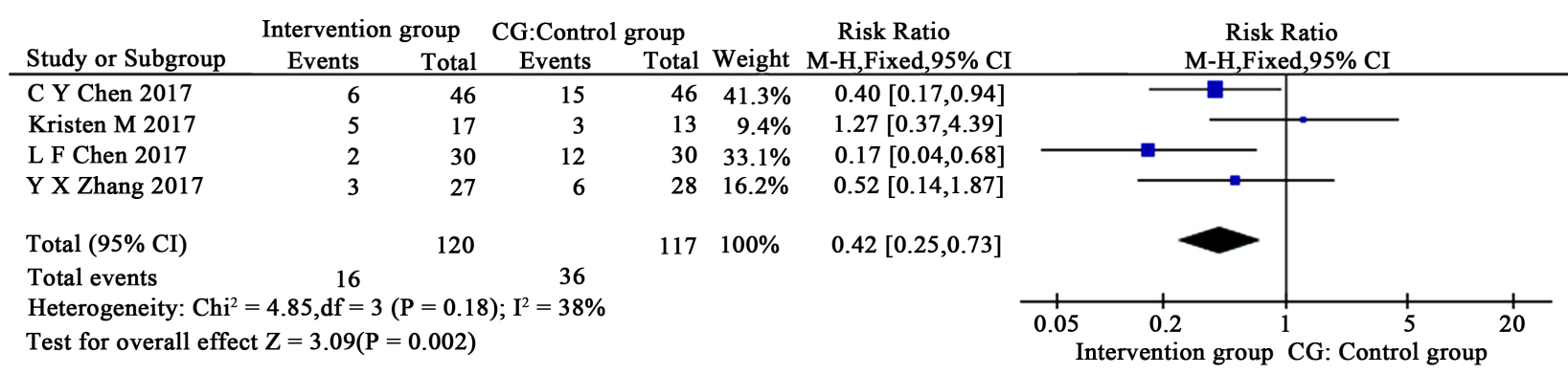

Figure 3. Effect of colostrums oral intervention on nosocomial infection.

However, because of the obvious clinical heterogeneity [17] of the measure method. Including venous blood, urine, saliva, and tracheal secretion, only descriptive analysis was conducted. Glass K found lactoferrin will significant increased after the colostrum intervention, but the change of the slgA is not statistically significant, the main reason is that $\operatorname{sg} \mathrm{A}$ in colostrums is highest on the first day after delivery, and then it goes down. However, the timing of oral intervention of colostrums was mostly 4 - 5 days after delivery, it was in the decline stage, so slgA was not significantly improved.

\subsubsection{Other Effects of Colostrum Oral Intervention}

4 articles [12] [14] [15] [16] reported feeding intolerance, merge the result shows: the intervention group and control group there was no significant difference results $[\mathrm{RR}=0.58,95 \% \mathrm{CI}(0.30,0.31), \mathrm{P}=0.10)$, namely the colostrum oral intervention cannot reduce the incidence of preterm infant feeding intolerance, 5 articles [9] [11] [14] [15] [16] reported necrotizing enter colitis, data merging results showed that colostrum oral intervention can effectively reduce the incidence of necrotizing enter colitis, there was no statistically significant difference in the two groups [14] [16] $(\mathrm{RR}=0.71,95 \% \mathrm{CI}(0.40,0.40), \mathrm{P}=0.25)$. Two articles reported the effect of colostrum oral instillation on hospitalization time of children, and the combined results showed that colostrum oral intervention could not effectively reduce the hospitalization time of children [MD = $-8.06,95 \%$ CI $(-21.00,4.88), \mathrm{P}=0.22$ ].

\subsection{Sensitivity Analysis}

Sensitivity analysis was performed for all the combined results. When sensitivity analysis was performed on the complete non-retention gestational age, the larg- 
est sample size Chen Caiyun was removed and the results changed, it is suggested that the result is not stable. As fewer than 10 articles were included, the funnel plot analysis was not done to evaluate the publication bias.

\section{Discussion}

\subsection{Methodological Quality Evaluation}

A total of 7 [9] [11]-[16] articles were included in this study, among which 5 [9] [11] [13] [14] [15] used random methods, 4 (57.1\%) [9] [11] [14] [15] explicitly stated the use of random numbers Table 1 [9] (14.2\%) reported the method of allocation concealment, and 1 [12] (14.2\%) only mentioned allocation concealment but did not specify the specific method. Seven (100\%) results use the blind method. Six [9] [11] [13] [14] [15] [16] (85.7\%) reported the loss of data, and 1 [9] (14.2\%) reported increased sample loss rate. All 6 [9] [11] [12] [13] [14] [16] studies $(85.7 \%)$ compared baseline levels of premature infants, and baseline consistency $(\mathrm{P}>0.05)$.

\subsection{Methods and Frequency of Colostrum Oral Intervention}

Colostrums oral intervention includes two forms, one is the colostrum oral drip, namely after removing the oropharyngeal secretions of premature infants, $0.2 \mathrm{ml}$ of normal temperature colostrum was extracted using $1 \mathrm{ml}$ syringe, along the side of the mouth, pointing to children with throat, uniform slowly push $0.1 \mathrm{ml}$, then moved to contralateral injection of $0.1 \mathrm{ml}$. The second is the colostrum smear, that is, after removing the oral secretions, use cotton swab to apply the colostrum restored to room temperature to the buccal mucosa of premature infants. 5 [9] [11] [12] [13] [14] used colostrum oral instillation, and 2 [15] [16] used colostrum oral smear. 4 [9] [12] [13] [14] performed on premature infants every 4 hours. 3 [15] [16] [18] performed every 3 hours, and one article [15] performed every 6 hours. 5 articles [9] [11] [12] [13] [14] indicated that each use of $0.2 \mathrm{ml}$ of colostrum, 4 articles [9] [12] [13] [14] lasted for 7 days and 1 article [16] lasted for two weeks.

\subsection{Colostrums Oral Intervention Can Accelerate the Process of Nutrition}

Premature infants often suffer from stomach retention, abdominal distension and vomiting due to immature digestive system [19]. Gastric retention, also known as gastric emptying delay, the results showed that the residual gastric fluid extracted from the stomach before feeding was more than $50 \%$ of the previous feeding. Complete non-retention is an indicator of complete recovery of gastrointestinal function and the amount of gastric residue in the normal range. The combined results of this study showed that the colostrum oral intervention can reduce the gestational age at the time of complete non-retention enhance the digestive function and promote the process of entreat nutrition. However, the stability of the combined results was poor, which may be attributed to the lack of 
a clear definition of feeding intolerance in some studies, and the inclusion of abdominal distension, vomiting and other factors into the tolerance range, which had an impact on the results.

\subsection{Early Colostrum Intervention Can Reduce Hospital Infection in Premature Infants}

Premature infants need to face the external environment alone after birth, but the each system is not mature, and the antibodies in breast milk cannot be obtained through mouth to resist external pathogenic bacteria, so the risk of infection is high. Studies have shown that the mother's colostrum of premature infants contains more cytokines and enzymes than that of full-term infant [18] [20] [21] [22]. These substances can be directly absorbed in the buccal mucosa to help premature infants resist external bacteria and development of premature infants. Therefore, the oral intervention of the colostomy of premature infants is more important than that of full-term infants. The combined results of the study also showed that the colostrum oral intervention can effectively reduce the incidence of nonsocial infection and promote the normal growth of premature infants [5] [11] [23].

\subsection{Effect on Immune Function}

Lactoferrin in colostrum has strong immunomodulatory, bactericidal, anti-infection and anti-virus effects [24], slgA and lactoferrin can be distributed on the oral mucosa surface and intervene oral colonization in the mouth, have the effect of local immunity, Lactoferrin and slgA are rarely used as evaluation indicator in domestic studies. But in foreign studies that are used as evaluation indexes, their measurement methods are too heterogeneous to be combined with data, According to specific research data, colostrum oral intervention can promote the increase of lactoferrin, but it has no significant advantage for $\operatorname{sg} \mathrm{A}$ growth [5] [25]. The main reason is that slgA content is the highest one day after giving birth and gradually decreases after that. However, the primary oral cavity intervention is mostly in the $4-5$ days after giving birth, which is in the decline stage of slgA. Therefore, the primary oral cavity intervention has no significant impact on slgA of premature infants.

\subsection{Limitations}

1) Only searched published Chinese and English articles, and did not search gray literatures. 2) Less than 10 studies were included without funnel plot analysis. 3) The domestic research in enteral feeding process for ending index, study abroad in the urine, saliva slgA and lactoferrin as the ending index, there is obvious heterogeneity, descriptive analysis only.

\section{Conclusion}

The methods, frequency, dosage and time of colostrum intervention were dif- 
ferent, so there are different views on the effects of colostrum intervention on gastrointestinal function and related diseases of premature infants. Now the homogeneous research is conducted for meta-analysis. The combined results showed that colostrum oral intervention can reduce the incidence of nosocomial infection; however, there was no advantage in necrotizing enters colitis, length of hospital stay, and feeding intolerance. The results showed that the gestational age of premature infants with complete non-retention could be reduced by colostrums intervention, but the stability of the results was poor, which needs further demonstration. Because slgA and lactoferrin were measured in different ways, only descriptive analysis was performed. It is suggested that the future study should be based on the urine slgA and lactoferrin, which do not cause damage to premature infants, and have comparability between studies. We should further explore the start time, frequency and duration of colostrums intervention in premature infants to form a standardized pattern of neonatal oral intervention.

\section{Conflicts of Interest}

The authors declare no conflicts of interest regarding the publication of this paper.

\section{References}

[1] Wang, D.H. (2014) Attention to Nutrition and Health of Premature Infants-Interpretation of International Consensus on Feeding Premature Infants. Chinese Journal of Contemporary Pediatrics, No. 7, 664-669.

[2] Corpeleijn, W.E., Chrisman, V., et al. (2016) Effect of Donor Milk on Severe Infections and Mortality in Very Low-Birth-Weight Infants. JAMA Pediatrics, 170, 654. https://doi.org/10.1001/jamapediatrics.2016.0183

[3] Seigel, J.K., Smith, P.B., Ashley, P.L., et al. (2013) Early Administration of Oropharyngeal Colostrum to Extremely Low Birth Weight Infants. Breastfeeding Medicine, 8, 491-495. https://doi.org/10.1089/bfm.2013.0025

[4] Rodriguez, N.A., Meier, P.P., Groer, M.W., et al. (2010) A Pilot Study to Determine the Safety and Feasibility of Oropharyngeal Administration of Own Mother's Colostrum to Extremely Low-Birth-Weight Infants. Advances in Neonatal Care, 10, 206-212. https://doi.org/10.1097/ANC.0b013e3181e94133

[5] Rodriguez, N.A., Meier, P.P., Groer, M.W., et al. (2009) Oropharyngeal Administration of Colostrum to Extremely Low Birth Weight Infants: Theoretical Perspectives. Journal of Perinatology, 29, 1-7. https://doi.org/10.1038/jp.2008.130

[6] Sheila, M. and Gephart, P.R. (2014) Colostrum as Oral Immune Therapy to Promote Neonatal Health. Evidence-Based Practice Briefs, 14, 44-51.

[7] Patra, K., Hamilton, M., Johnson, T.J., et al. (2017) NICU Human Milk Dose and 20-Month Neurodevelopmental Outcome in Very Low Birth Weight Infants. Neonatology, 112, 330-336. https://doi.org/10.1159/000475834

[8] Xia, H.P. and Zhu, Ji.X. (2015) Feeding Intolerance in Premature Infants. Chinese Journal of Applied Pediatrics, 30, 95-99.

[9] Zhang, Y., Ji, F., Hu, X., et al. (2017) Oropharyngeal Colostrum Administration in Very Low Birth Weight Infants. Pediatric Critical Care Medicine, 18, 869-875. https://doi.org/10.1097/PCC.0000000000001221 
[10] Julian, H. and Se, G. (2011) Cochrane Handbook for Systematic Reviews of Interventions Version 5.1.0. The Cochrane Collaboration.

[11] Glass, K., Greecher, C. and Doheny, K. (2017) Oropharyngeal Administration of Colostrum Increases Salivary Secretary IgA Levels in Very Low-Birth-Weight Infants. American Journal of Perinatology, 34, 1389-1395. https://doi.org/10.1055/s-0037-1603655

[12] Ji, F.T., Zhang, Y.X., et al. (2016) Effect of Colostrum Oral Instillation on Feeding Status of Very Low Birth Weight Infants. Chinese Journal of Nursing, No. 10, 1157-1160.

[13] Zhao, X.J. (2017) Effects of Oral Instillation of Colostrum on Digestive and Immune Functions of Very Low Birth Weight Infants. Maternal and Child Health Care in China, No. 17, 4182-4184.

[14] Chen, C.Y. and Zhu, C.J. (2018) Application Value of Colostrum Oral Instillation in the Feeding of Ultra-Low Birth Weight Infants. Health Profession Education, No. 3, 155-156.

[15] Cao, S.X. and Zeng, G.L. (2018) Effects of Colostrum Oral Immunotherapy on Enteral Nutrition and Gastrointestinal Hormone Levels in Premature Infants. Medical Theory and Practice, No. 3, 324-325.

[16] Chen, L.F. and Zhang, L. (2017) Effect of Colostrum on Extremely Low Weight Premature Infants. Journal of Qilu Nursing, No. 18, 114-116.

[17] Rodriguez, N.A., Vento, M., Claud, E.C., et al. (2015) Oropharyngeal Administration of Mother's Colostrum, Health Outcomes of Premature Infants: Study Protocol for a Randomized Controlled Trial. Trials, 16, 453. https://doi.org/10.1186/s13063-015-0969-6

[18] Guo, M., Tang, X.Y., et al. (2015) Systematic Evaluation and Meta-Analysis of Probiotics in the Prevention of Necrotizing Enterocolitis in Premature Infants. Chinese Journal of Evidence-Based Pediatrics, 11, 401-408.

[19] Snyder, R., Herdt, A., Mejias-Cepeda, N., et al. (2017) Early Provision of Oropharyngeal Colostrum Leads to Sustained Breast Milk Feedings in Preterm Infants. Pediatrics \& Neonatology, 58, 534-540. https://doi.org/10.1016/j.pedneo.2017.04.003

[20] Thibeau, S. and Boudreaux, C. (2013) Exploring the Use of Mothers' Own Milk as Oral Care for Mechanically Ventilated Very Low-Birth-Weight Preterm Infants. Advances in Neonatal Care, 13, 190-197. https://doi.org/10.1097/ANC.0b013e318285f8e2

[21] Liu, L.X. and Zhang, Y.X. (2014) Advances in Non-Drug Interventions for Apnea in Premature Infants. Chinese Journal of Nursing, No. 1, 99-103.

[22] Lu, T.C., Zhang, Y.X. and Hu, X.J. (2013) Effect Evaluation of Early Oral Motion Intervention Program to Improve Oral Feeding in Premature Infants. Chinese Journal of Nursing, 48, 101-105.

[23] O’Connor, D.L., Gibbins, S., Kiss, A., et al. (2016) Effect of Supplemental Donor Human Milk Compared with Preterm Formula on Neurodevelopment of Very Low-Birth-Weight Infants at 18 Months. JAMA, 316, 1897.

https://doi.org/10.1001/jama.2016.16144

[24] Marcuzzi, A., Vecchi Brumatti, L., Caruso, L., et al. (2012) Presence of IL-9 in Paired Samples of Human Colostrum and Transitional Milk. Journal of Human Lactation, 29, 26-31.

[25] Lee, J., Kim, H.S., Jung, Y.H., et al. (2015) Oropharyngeal Colostrum Administration in Extremely Premature Infants: An RCT. Pediatrics, 135, e357-e366.

https://doi.org/10.1542/peds.2014-2004 